\title{
INJURY EPIDEMIOLOGY IN THE FIRST CROATIAN BASKETBALL LEAGUE
}

\author{
Matilda Šola and Cvita Gregov \\ Faculty of Kinesiology, University of Zagreb, Zagreb, Croatia
}

Original scientific paper

DOI: $10.26582 / \mathrm{k} .53 .1 .19$

\begin{abstract}
:
The aim of this study was to provide a retrospective overview of injuries during one basketball season and to analyse injury rates and potential risks among professional male and female basketball players in the First Croatian National league. A hundred and forty-two (89 males and 53 females) of 223 basketball players $(64 \%)$ sustained an injury during the previous season. Body height, total game exposure and total on-court time per game $(p<.05)$ were the identified risk factors for females, while the number of training hours per week was found to be a risk factor for males $(\mathrm{p}<.05)$. The highest proportion of injured players was found among centers for men (74\%) and forwards (70\%) for women. Forty-three percent of injuries were moderately serious, $31 \%$ were minor, and $20 \%$ were serious injuries. The majority ( $80 \%$ ) of all injuries were to the lower extremities and men sustained fewer lower extremity injuries compared to women (IRR $=0.88$ $95 \% \mathrm{CI}=0.6$ to 1.3 ). Ankles were the most prevalent injury site for both men and women followed by the knee. Men sustained significantly fewer knee injuries compared to female athletes (IRR $=0.4495 \% \mathrm{CI}=0.17$ to 1.11$)$. The most common injury type was ligament injuries (31\%), followed by muscle tears/strains (20\%). Game incidence injury rate for males was significantly lower than for females (IRR $=0.55, p=0.01[95 \%$ $\mathrm{CI}=0.34-0.89])$. Those athletes who, on average, played more than 20 minutes in games were almost twice more exposed to an injury $(\mathrm{OR}=2.09,95 \% \mathrm{CI}=1.17,3.72)$. This is the first descriptive epidemiological study estimating rates and risks of injuries among the Croatian professional basketball players.
\end{abstract}

Key words: professional players, injury rates, risk factors, prevention

\section{Introduction}

Basketball has evolved to become a highly physical sport with high injury rates (Drakos, Domb, Starkey, Callahan, \& Allen, 2010). As the sport of basketball has changed significantly so have the demands on the players. Game has become physically more demanding, training and competition load has increased, consequently leading to an increase in the number of injuries. High participation rates in basketball have led to increased number of injuries, especially in female basketball where there is consistently a higher pattern of injury rate compared with men since 1989 to 1998 (Arendt, Agel, \& Dick, 1999). Basketball poses one of the highest risks of injury in team sports, with injury rates up to 10 injuries per 1000 athletic exposures (Taylor, Ford, Nguyen, Terry, \& Hegedus, 2015). For this reason, interest in the type and mechanism of basketball-related injuries has grown (Kofotolis \& Kellis, 2007). Studies addressing the epidemiology of basketball injuries have been very popular in the US (Andreoli, et al., 2018; Arendt, et al., 1999; Deitch, Starkey, Walters, \& Moseley, 2006; Henry, Lareau, \& Neigut, 1982; Messina, Farney, \& DeLee,
1999; Zelisko, Noble, \& Porter, 1982) and research has focused mainly on professional levels (Baker, Rizzi, \& Athiviraham, 2020; Deitch, et al., 2006; Drakos, et al., 2010; Henry, et al., 1982; Zelisko, et al., 1982 ) or high school/collegiate players (Agel, et al., 2007; Meeuwisse, Sellmer, \& Hagel, 2003; Messina, et al., 1999; Venderlei, et al., 2013; Zuckermann, et al., 2016,). However, there is a lack of research on basketball injury epidemiology in Europe, although basketball is played widely and is very popular in Europe (Passanen, et al., 2017). Before translating injury data resulting from epidemiological studies performed in the US to European players, it has to be considered that the game of basketball as played in the US is different from its European counterpart, which is partly caused by the different rules (Cumps, Verhagen, \& Meeusen, 2007). Although evidence is limited and the variety in data collection and game characteristics makes studies challenging for comparisons, European epidemiological studies (Cumps, et al., 2007; Kofotolis \& Kellis, 2007; Passanen, et al., 2017) are in agreement with the US studies (Drakos, et al., 2010; Messina, et al., 1999; Tummala, Hartigan, Mako- 
vicka, Patel, \& Chhabra, 2018; Zuckermann, et al., 2018) indicating that a large proportion of basketball-related injuries consists of lower extremity injuries. Specifically, the most injured are ankle and knee joints, and the highest prevalence is found in ligament sprains and muscle strains (Baker, et al. 2020; Cumps, et al., 2007; Deitch, et al., 2006; Drakos, et al. 2010; Herzog, et al., 2019; Kotofolis \& Kellis, 2007; Messina, et al., 1999; Owoeye, akodu, Oladokun, \& Akinbo, 2012; Passanen, et al., 2017; Rodas, et al., 2019; Zuckermann, et al., 2018). The understanding of basketball injury epidemiology, establishment of aetiology and mechanisms of injuries is an important base for future injury prevention recommendations (Finch, 2006).

Despite plenty of the US descriptive epidemiological studies of women's and men's basketball injuries, there is not a great deal of epidemiological data to be found on injuries of basketball players in the European countries (Benis, La Torre, \& Bonato, 2018), and especially in Croatia. For this reason, the aim of this study was to describe the epidemiology of injuries among the women's and men's professional basketball leagues in Croatia. Moreover, the objective of this study was to provide a retrospective overview of injuries during one basketball season (2017/2018), and to analyse injury rates and potential risks among professional male and female basketball players in the First Croatian National league.

\section{Methods}

Using a retrospective design, 21 out of 24 (12 men's and 12 women's teams) professional basketball teams competing in the First Croatian basketball league volunteered to participate in this study (12 men's and 9 women's teams) with a total of 223 players (137 male and 86 female players). All athletes signed an informed consent form. Injuries, personal data, and training data were collected retrospectively by their team coaches and/or physicians using an injury questionnaire designed for the purposes of this study. All players were instructed to record all-complaint injuries during the previous season 2017/2018. An all-complaint injury was defined as any physical complaint, including pain, ache, joint instability, stiffness, or any other complaint including but irrespective of the need for medical attention or time-loss (Fuller, et al., 2006, according to Owoeye, et al., 2020). Information on the anthropometric data (age, body height, body mass, body mass index), and the playing positions for athletes were noted. The questionnaire included the information on the type of the injury, its localization, impact of the injury on training regimen, a type of session when the injury occurred, injury mechanism (acute or gradual onset), time-loss, medical attention, time of the injury regarding the part of the season. The number of matches/games for each team/club were collected using online available data of the Croatian Basketball Federation for the competitive season in question (https:// www.hks-cbf.hr/), then the duration (in weeks) of the competitive season for each team was calculated (from the first to the final match). Players were asked to note an average number of training sessions per week and their duration specifically for the preparatory and competition period, as well as their personal average time spent on the court during the games (four categories). We used that information to calculate total exposure time to injury for each player combining the practice and game exposure time.

Game exposure time was calculated as the average time spent on the court multiplied by the number of games played by each team. Total practice exposure time was the number of training sessions per week multiplied by an average duration of training sessions and the total number of weeks for a certain part of the season. Practice exposure was calculated separately for the preparatory and competition period of the season. The duration of the preparatory period was eight weeks for both genders, while the duration of the competitive period varied among clubs depending on the number of games. The rate of injury (incidence rate-IR) was assessed as the number of injuries per 1000 basketball exposure hours. Incidence rate ratio was calculated to compare the injury incidence between the groups. Injury severity was classified based on the working time lost from basketball games and/ or practices as follows: minor ( $0-7$ days loss from basketball), moderate (8-21 days loss) and severe ( $>21$ days loss from basketball). Risk factors were analysed in association with the participants' age, height, body mass, training exposure time, injury severity, injured area, injury circumstances (practice session vs. games), injury timing within the season, playing position, and correlation between players' participation in games (total playing time) and injury occurrence.

Descriptive statistics was calculated for demographic information. Chi-squared tests were used to investigate significant differences between the recorded values and their expected distribution; more specifically, to examine the differences in injury incidence rates between different playing positions and injury mechanisms. A $t$-test was used to determine the statistical difference between the injured and uninjured players in anthropometric data and exposure time. A one-way ANOVA test was performed to estimate the statistical difference among the playing positions in players' anthropometric characteristics. For suitable variables, the odds ratio was estimated as the odds of exposure to injury among the injured athletes compared with the odds of exposure among the uninjured athletes. The level of significance for each test was set at $\mathrm{p}<.05$. 


\section{Results}

In this retrospective study 142 (89 males and 53 females) out of 223 athletes, or $64 \%$, sustained an injury during the previous season; 25 of which reported more than one injury (17 males and 8 females) corresponding to a total of 196 injuries (117 for men and 79 for women).

The mean number of training sessions per week, their duration, and the duration of the period of the season with their standard deviation values are presented in Table 1.

Injury incidence rate expressed as the number of injuries $/ 1000 \mathrm{~h}$ was as follows: $\mathrm{IR}=1.75$ $(95 \% \mathrm{CI}=15.14-20.14)$ for both genders; IR $=1.62$ $(95 \% \mathrm{CI}=13.42-19.45)$ for men and $\mathrm{IR}=2.25(95 \%$ $\mathrm{CI}=17.79-28.0)$ for women.

\section{Descriptive statistics}

Anthropometric data and exposure time for the uninjured and injured athletes are presented in Table 2.
The injured athletes did not differ from the uninjured athletes regarding their age, body mass, or BMI. However, the significant difference was found regarding body height $(\mathrm{t}=-3.16, \mathrm{p}=.002)$, on-court time in minutes per game $(\mathrm{t}=-2.14, \mathrm{p}=.04)$ and total game exposure $(\mathrm{t}=-2.54, \mathrm{p}=.01)$. The injured male players had significantly more training hours per week during the preparatory period $(\mathrm{t}=-2.02, \mathrm{p}=.05)$ than the uninjured players.

\section{Anthropometric differences by players' positions and gender}

There were 112 guards ( 60 men, 52 women), 74 forwards (54 men, 20 women) and 37 centers (23 men, 14 women). Anthropometric data by playing positions and gender are presented in Table 3 .

There was a significant difference, as expected, in players' anthropometric characteristics (body height, body mass, BMI) among the playing positions. Furthermore, post-hoc tests showed that there was a significant difference between each playing

Table 1. Number of training sessions and duration of season periods and trainings

\begin{tabular}{lcc}
\hline & Men & Women \\
\hline No. of training sessions/week CP & $8.14( \pm 2.09)$ & $7.05( \pm 1.9)$ \\
Duration of trainings CP $(\mathrm{min})$ & $101.77( \pm 17.49)$ & $96.63( \pm 21.26)$ \\
Duration of the CP (weeks) & $29.56( \pm 2.33)$ & $27.08( \pm 1.32)$ \\
No. of training sessions/week PP & $9.37( \pm 2.1)$ & $7.44( \pm 2.72)$ \\
Duration of trainings PP (min) & $112.30( \pm 16.86)$ & $100.23( \pm 25.23)$ \\
Duration of the PP (weeks) & 8 & 8 \\
\hline
\end{tabular}

Note. CP-competitive period, $\mathrm{PP}$ - preparatory period.

Table 2. Descriptive statistics and exposure for the injured vs. uninjured players

\begin{tabular}{|c|c|c|c|c|c|c|c|}
\hline & & \multicolumn{2}{|c|}{ Uninjured } & \multicolumn{2}{|c|}{ Injured } & \multirow[b]{2}{*}{$t$-value } & \multirow[b]{2}{*}{$p$-value } \\
\hline & & $M$ & $\mathrm{~N}$ & $M$ & $\mathrm{~N}$ & & \\
\hline \multirow[t]{2}{*}{ Age (year) } & $M$ & 24.13 & 48 & 23.76 & 89 & 0.25 & 0.80 \\
\hline & W & 19.70 & 33 & 19.23 & 53 & -0.26 & 0.80 \\
\hline \multirow[t]{2}{*}{ Body height $(\mathrm{cm})$} & M & 196.19 & 48 & 198.16 & 89 & -1.38 & 0.17 \\
\hline & W & 173.79 & 33 & 178.51 & 53 & -3.16 & $0.00^{*}$ \\
\hline \multirow[t]{2}{*}{ Body mass (kg) } & M & 94.54 & 48 & 95.30 & 89 & -0.32 & 0.75 \\
\hline & W & 66.30 & 33 & 67.62 & 53 & -0.62 & 0.54 \\
\hline \multirow[t]{2}{*}{ BMI $\left(\mathrm{kg} / \mathrm{m}^{2}\right)$} & M & 24.54 & 48 & 24.21 & 89 & 0.69 & 0.49 \\
\hline & W & 21.76 & 33 & 21.23 & 53 & 1.02 & 0.31 \\
\hline \multirow[t]{2}{*}{ Total game exposure $(\mathrm{h})$} & M & 11.69 & 48 & 11.82 & 89 & -0.13 & 0.90 \\
\hline & W & 8.10 & 33 & 10.51 & 53 & -2.54 & $0.01^{*}$ \\
\hline \multirow[t]{2}{*}{ On-court minutes per game } & M & 27.38 & 42 & 27.33 & 86 & 0.03 & 0.98 \\
\hline & W & 23.44 & 32 & 28.68 & 53 & -2.14 & $0.04^{*}$ \\
\hline \multirow[t]{2}{*}{ Weekly hours of training $\mathrm{CP}$} & M & 11.78 & 48 & 13.54 & 89 & -1.71 & 0.09 \\
\hline & W & 9.73 & 33 & 11.51 & 53 & -1.67 & 0.10 \\
\hline \multirow[t]{2}{*}{ Weekly hours of training PP } & M & 14.03 & 48 & 16.65 & 89 & -2.02 & $0.05^{*}$ \\
\hline & w & 12.89 & 53 & 11.04 & 33 & 1.30 & 0.20 \\
\hline
\end{tabular}

Note. *statistically significant, $\mathrm{p}<.05$; t-test; $\mathrm{CP}$-competition period; PP_-preparatory period. 
Table 3. Anthropometric data of players by playing positions

\begin{tabular}{|c|c|c|c|c|c|c|c|c|}
\hline & & \multicolumn{2}{|c|}{$\begin{array}{c}\text { Guard } \\
(M=60, W=52)\end{array}$} & \multicolumn{2}{|c|}{$\begin{array}{c}\text { Center } \\
(M=23, W=14)\end{array}$} & \multicolumn{2}{|c|}{$\begin{array}{c}\text { Forward } \\
(\mathrm{M}=54, \mathrm{~W}=20)\end{array}$} & \multirow[b]{2}{*}{$p$-value } \\
\hline & & M & SD & M & SD & $\mathbf{M}$ & SD & \\
\hline \multirow{2}{*}{ Age (year) } & $\mathrm{M}$ & 23.82 & 5.51 & 24.00 & 4.75 & 23.93 & 4.71 & 0.88 \\
\hline & W & 18.69 & 4.20 & 18.71 & 3.75 & 21.75 & 5.72 & 0.10 \\
\hline \multirow{2}{*}{ Body height $(\mathrm{cm})$} & $\mathrm{M}$ & 190.78 & 6.18 & 207.43 & 2.76 & 200.65 & 3.69 & $0.00^{*}$ \\
\hline & W & 173.13 & 6.32 & 183.14 & 4.44 & 181.45 & 3.91 & $0.00^{*}$ \\
\hline \multirow{2}{*}{ Body mass $(\mathrm{kg})$} & $\mathrm{M}$ & 85.65 & 5.35 & 108.43 & 7.29 & 99.76 & 14.34 & $0.00^{*}$ \\
\hline & W & 62.83 & 7.40 & 76.71 & 9.85 & 71.55 & 7.48 & $0.00^{*}$ \\
\hline \multirow{2}{*}{ BMI $\left(\mathrm{kg} / \mathrm{m}^{2}\right)$} & $\mathrm{M}$ & 23.58 & 1.93 & 25.20 & 1.66 & 24.78 & 3.48 & $0.00^{*}$ \\
\hline & W & 20.93 & 2.04 & 22.89 & 3.01 & 21.73 & 2.23 & $0.00^{*}$ \\
\hline
\end{tabular}

Note. *statistically significant, $p<.05$; ANOVA tests.

position for men in height ( $\mathrm{p}=.00$ ), whereas for women it was found between guards and centers $(\mathrm{p}=.00)$ and guards and forwards $(\mathrm{p}=.00)$. The same effect was found in the body mass variable - there was a significant difference among all the positions for men (guard vs. center $\mathrm{p}=.00$, guard vs. forward $\mathrm{p}=.00$, forward vs. center $\mathrm{p}=.002$ ), while forwards and centers did not significantly differ among the female players $(p>05)$. Guards and centers differed in BMI (men: $p=.04$, women: $p=.015$ ). There was no difference between the playing positions regarding players' age.

\section{Severity and impact of injuries on practice regimen}

The highest proportion of injured players was found among centers for men 74\% (38/60) and forwards 70\% (14/20) for women but no statistically significant difference was found in incidence rate among the playing positions $\left(\chi^{2}=0.97, \mathrm{p}=.61\right.$ for men; $\chi^{2}=1.39, p=.51$ for women). Most injuries $(43 \%)$ were described as moderately serious, causing 8-21 training/competition days lost, while there was $31 \%$ of minor (1-7 days lost) and $20 \%$ of serious injuries, causing more than 21 days lost; $7 \%$ of injuries did not causepractice/competition absence. Figure 1 shows injury severity according to the playing positions (the non-time loss injuries were not included).

Centers sustained the highest percentage of serious injuries (35\%) followed by guards, while forwards had the highest percentage of minor injuries $(38 \%)$.

Half of the athletes indicated that their injury caused cessation in training, while $42 \%$ indicated that the reported injury caused them to slightly change their exercise/training regimen (Pearson $\left.\chi^{2}: 1.59, \mathrm{p}=.66\right)$.

\section{Injured region}

The most frequently injured locations were the ankle 39\% (58/147) and knee 15\% (22/147) (Figure

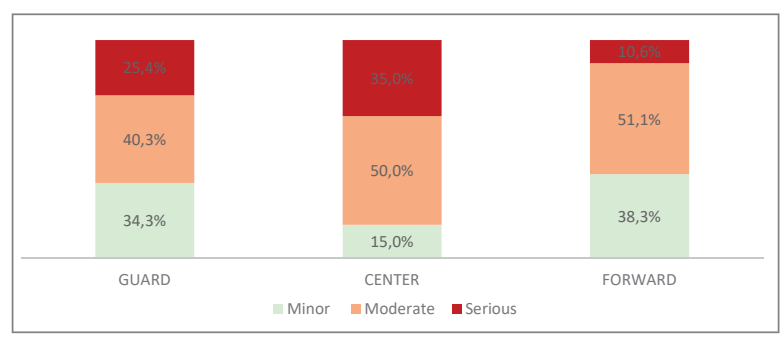

Figure 1. Injury severity by playing positions.

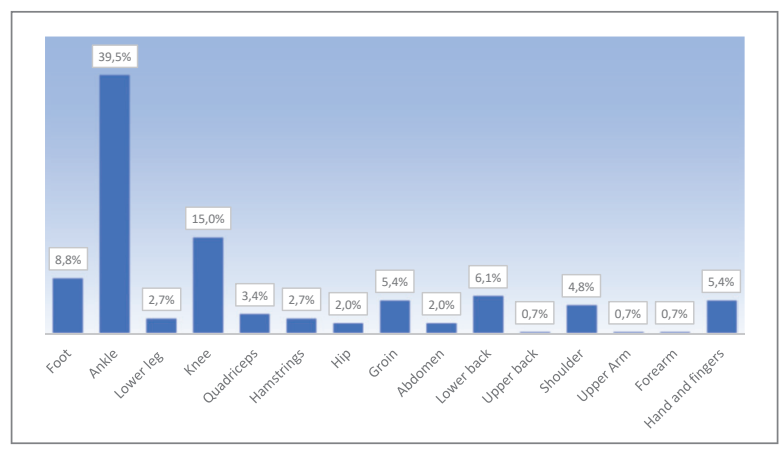

Figure 2. Injuries by body regions.

2); $80 \%$ of all injuries were to the lower extremities.

Men sustained slightly fewer lower extremity injuries compared to women (IRR $=0.88$ 95\% $\mathrm{CI}=0.6$ to 1.3 ). The ankle was the most common injury site for both men and women (IRR $=0.9638$ $95 \% \mathrm{CI}=0.55$ to 1.71 ) accounting for approximately $40 \%$ of all the injury sites reported, followed by the knee, which accounted for $10 \%$ of the injured sites in men and $22 \%$ in women. Men sustained significantly fewer knee injuries compared with the women athletes (IRR $0.4495 \% \mathrm{CI}=0.17$ to 1.11 ). The proportion of the upper extremity injuries was $20 \%$; men sustained significantly more upper extremity injuries compared to the women athletes ( $\mathrm{IRR}=1.7495 \% \mathrm{CI}=0.75$ to 4.52 ).

\section{Types and mechanisms of injuries}

Out of all the reported injuries $48 \%$ were preexisting ones or re-injuries ( $44 \%$ for men, $55 \%$ for 
Table 4. Types of injuries

\begin{tabular}{lcccc}
\hline & Guard & Center & Forward & SUM \\
\hline Not sure & 7 & 2 & 7 & 16 \\
Muscle tear/strain & 17 & 3 & 10 & 30 \\
Tendon tear/strain & 9 & 4 & 6 & 19 \\
Ligament tear/sprain or meniscus & 19 & 12 & 15 & 46 \\
Bone fracture & 1 & 0 & 2 & 3 \\
Laceration & 2 & 0 & 2 & 4 \\
Cartilage damage & 4 & 2 & 2 & 8 \\
Other & 13 & 2 & 7 & 22 \\
\hline
\end{tabular}

Table 5. Burden of injuries (days lost) by injury types

\begin{tabular}{lcccc}
\hline Injury type & 0 days & 1 to 7 days & 8 to 21 days & $>21$ days \\
\hline Not sure & 2 & 2 & 9 & 2 \\
Muscle tear/strain & 1 & 11 & 16 & 1 \\
Tendon tear/strain & 2 & 5 & 8 & 0 \\
Ligament tear/sprain or meniscus & 2 & 13 & 0 & 2 \\
Bone fracture & 0 & 0 & 2 & 2 \\
Laceration & 0 & 0 & 1 & 6 \\
Cartilage damage & 1 & 10 & 7 & 1 \\
Other & 1 & & & \\
\hline
\end{tabular}

women) $\left(\chi^{2}=1.43, p=0.23\right)$. There was a significant difference in incidence rate regarding the injury mechanism: $80 \%(113 / 141)$ of all injuries were acute ones with a sudden onset, whereas a small proportion were chronic ones $(28 / 141)\left(\chi^{2}=4.18, p=.04\right)$. According to the reported injury type, the most prevalent were ligament injuries 31\% (46/148), the second most prevalent were muscle tears/strains $20 \%(30 / 148)$ and tendon tears/strains 13\% (19/148) (Table 4).

Ten players reported more than 21 practice and competition days lost due to ligament injuries, 17 players lost 8-21 days, while 13 players reported this type of injury caused training cessation of 1-7 days. Muscle tears/strains among 16 players caused 8-21 days lost, while 11 players reported this type of injury caused them to lose 1-7 days (Table 5).

\section{Injury occurrence in games vs. practices and part of the season}

Most injuries were sustained in practice by both males (66\%) and females $(58 \%)\left(\chi^{2}=3.86\right.$, $\mathrm{p}=.28)$. The game injury rate for male players was $24.18 / 1000 \mathrm{~h}(95 \% \mathrm{CI}=17.19-33.05)$ and for female players $\mathrm{IR}=43.69 / 1000 \mathrm{~h}(95 \% \mathrm{CI}=30.6-60.48)$. Therefore, men were less likely to sustain an injury during a match compared to women (IRR $=0.55$, $\mathrm{p}=0.01([95 \% \mathrm{CI}=0.34-0.89])$. The practice injury rate was $0.85 / 1000 \mathrm{~h}(95 \% \mathrm{CI}=0.65-1.1)$ for males and $0.94 / 1000 \mathrm{~h}(95 \% \mathrm{CI}=0.65-1.33)$ for females. Men were slightly less prone to injury during practice
IRR $=0.9(95 \% \mathrm{CI}=0.58-1.43)$. Regarding the part of the season, a vast majority of the injuries happened in-season (79\%) and required medical attention $(86 \%)$.

\section{Injury risk}

Regarding the players' participation in games, athletes indicated the time spent on the court during games as less than $10 \mathrm{~min}, 10$ to 20 minutes, 20 to 30 minutes, more than 30 minutes. We found that those athletes who, on average, played more than 20 minutes in games were almost twice more exposed to an injury $(\mathrm{OR}=2.09,95 \% \mathrm{CI}=1.17,3.72)$.

\section{Discussion and conclusion}

Within the 8-month period, $64 \%$ of athletes sustained an injury during the previous season, corresponding to the total of 196 injuries (117 for men and 79 for women). This proportion is similar to those reported by Cumps et al. (2007) (67.7\%) and Henry et al. (1982) (69\%). Injury incidence rate was $1.75 / 1000 \mathrm{~h}$ (1.6 for men and 2.2 for women). A direct comparison of the injury rate found in this study with the rates found by other investigators is difficult because of various factors and different methodologies used, such as incidence rate calculations, definitions of injuries, competition levels, and sex of players. In the study which used the same definition of injuries, Owoeye et al. (2020) found a much higher rate of injuries $13.8 / 1000 \mathrm{~h}$ in females and 14.8/1000h in males. However, players 
were observed throughout one competitive basketball season which did not include the preparatory period and the study was conducted with highschool and club basketball players. In studies with the European basketball players, the incidence rate of injuries varies. Passanen et al. (2017) reported the overall rate of injury for young female and male basketball players was 2.64 per $1000 \mathrm{~h}$, which was similar to the result among the Croatian basketball players $(1.75 / 1000 \mathrm{~h})$. In the first prospective study on a European count throughout the 32-week season Cumps et al. (2007) reported incidence rate of 8.0 injuries/1000h for men and 13.9/1000h for women. Another European study (Rodas, et al., 2019) with professional male basketball players reported that the general injury rate over nine seasons was 10.8 injuries per 1000 player-hours (95\% CI, 9.9-11.9). These studies showed a higher incidence rate of injuries, which might be due to the limitation in our methodology and big influence of recall bias.

We found no differences among the injured and uninjured athletes regarding their age, body mass or BMI, but found a significant difference among females regarding the body height variable $(t=-3.16$, $\mathrm{p}=.002$ ). These results demonstrate that individual characteristics of women, height in particular, may be related to the occurrence of injuries. A greater height in the sport with constant excessive joint loads and dynamic and explosive actions seems to be a risk factor. This may be due to longer levers so torques and loads to the lower extremities are so big that higher women are not able to withstand it and injuries occur. Generally, the biotype of players is considered to be a determining factor regarding the position played on the court (Neto \& César, 2005, acccording to Vanderlei, et al., 2013), but there are inconsistent findings about the relationship of players' characteristics and injury occurrence. On the one hand, Drakos et al. (2010) reported that there were no correlations between injury rate and height, body mass, or years of NBA experience among male professional players. On the other hand, Vanderlei et al. (2013) demonstrated that individual characteristics of players might be related to injury occurrence. In particular, they found that body mass might be a risk factor for all the playing positions; statistically higher values were reported relating to age and height of shooting guards and centers who had suffered injuries in the previous 12 months in comparison to the noninjured participants (Vanderlei, et al., 2013). Further research addressing player demographics is needed to identify injury risk factors. These findings may be essential, given that agents and organizations are constantly trying to predict injury risk for each player based on his/her demographic information (Drakos, et al., 2010). Ostojic, Mazic, and Dikic (2006) in their study with 60 professional Serbian basketball players demonstrated a strong relation- ship between body composition and positional roles in elite basketball. This supports results of our study and previous statement (Neto \& César, 2005), which indicates that players in different playing positions on the court statistically significantly differ in individual characteristics (height, body mass, BMI).

Our results showed that the highest proportion of injured players was found among centers for males (74\% of all the injuries) and forwards among females $(70 \%)$. However, no significant difference was found in injury incidence rate among males and females in different playing positions $\left(\chi^{2}=0.97\right.$, $\mathrm{p}=.61$ for males, $\chi^{2}=1.39, \mathrm{p}=.51$ for females). Centers seem to have the highest rate of injuries among male players which may be related to their role in the game. Their responsibility on the court is scoring throws from within the key; it also involves catching as many rebounds as possible that require the use of brute force when fighting for space with a lot of physical contact (Vanderlei, et al., 2013). Moreira, Gentil, and Oliveira (2003) analysed professional adult players and found a greater frequency of injuries among centers, followed by guards. Meeuwisse et al. (2003) also found centers to have the highest incidence rate for all injuries and forwards to have the lowest injury rate. However, in the 10-year epidemiology study on men's and women's collegiate basketball, it was found that among male and female players guards had a significantly higher ankle injury rate than forwards and centers (Tummala, et al. 2018). It should be noted that this study focused on ankle injuries only.

In regard to practice and competition time loss due to injuries, centers had the highest proportion of serious injuries ( $>21$ days lost) followed by guards regardless of gender. Center is a position in which constant contacts between players occur so that may explain more serious injuries. Our findings reported $43 \%$ of moderate injuries, $31 \%$ of minor injuries and $20 \%$ of serious injuries. Moderate injuries represented the most frequent type of injury (41\%) in the study by Passanen et al. (2017) as well. Lower extremity injuries are the most common injuries in basketball accounting for up to $90 \%$ of all injuries (90\% in Rodas, et al., 2019; 88\% in Owoeye, et al., 2020; 78\% in Pasanen, et al., 2017; 73\% in Baker, et al., 2020; 55 and 67\% in Zuckermann, et al., 2018; 65\% in Deitch, et al., 2006; 65\% in Andreoli, et al., 2018; 62\% in Drakos, et al., 2010). Results in our study, where lower extremity injuries accounted for $80 \%$ of all the injuries, are also in the reported interval.

Not surprisingly, the ankle was the most prevalent injury site accounting for approximately $40 \%$ of all the injury sites reported, followed by the knee, which accounted for $15 \%$ of all the injuries $(10 \%$ of injured sites in men and $22 \%$ in women). The ankle and knee were the most frequently injured body parts regardless of gender. Most authors point to the 
ankle and knee as the most common site of injury and our results are consistent with those studies. It was reported that ankle injuries accounted from $15 \%$ up to $50 \%$ of all the injuries and knee injuries accounted from 15 to 29\% (Baker, et al., 2020; Deitch, et al., 2006; Drakos, et al., 2010; Harmer, 2005; Herzog, et al., 2019; Messina, et al., 1999; Passanen, et al., 2017)

When compared to females, males sustained significantly fewer lower extremity injuries $(I R R=0.88)$ and fewer knee injuries $(I R R=0.44)$. These data are comparable with the other studies. Deitch at al. (2006) compared injury rates in women's and men's professional basketball (WNBA and NBA) and reported more lower extremity injuries among female athletes $\left(\chi^{2}=9.6, p<.01\right)$. Passanen et al. (2017) in their follow-up study on eight basketball teams reported similar results according to the distribution of ankle and knee injuries among males and females. The two most frequently injured body parts in females and males were ankles and knees, but females sustained a larger proportion of knee injuries (19\% vs $11 \%$ ). Knee injuries constituted $16 \%$ of the women's injuries and $12 \%$ of the men's in a study by Zelisko et al. (1982). Zuckermann et al. (2016) also reported higher knee injury rates among female collegiate players in comparison with their male counterparts. However, these findings are in contrast with the recent finding on all-complaint injuries reported by Owoeye et al. (2020) who, among 518 players from Canada, found that the knee was the most commonly injured body location in males $(50.5 \%)$, while the ankle was in females (45.1\%). Although the overall rate and incidence of injuries between males and females may vary, gender difference did not have a significant impact on altering the nature and distribution of the most frequent basketball-related injuries.

Ligament tears/sprains were the most prevalent injury type (31\%) followed by muscle tears/ strains (20\%). Taylor et al. (2015) in their metaanalysis reported that ankle sprains, especially lateral ankle sprains, are the most commonly diagnosed injury in both male and female basketball players, accounting for approximately $25 \%$ of all injuries. Further, Herzog et al. (2019) reported that ankle sprains affected $26 \%$ of NBA players on average each season and the incidence of those with a previous history of ankle sprain was 1.41 times higher compared to those without a history of ankle sprain. Passanen et al. (2017) found also that joint/ligament injuries were the most frequent type of injury for both female (69\%) and male (66\%) adolescent basketball players in a 3-year prospective follow-up study. However, these percentages are higher than those found in our study. On the contrary, Rodas et al. (2019) in their 9-year prospective follow-up study in professional men's basketball reported higher frequency of muscle injuries
$(\mathrm{IR}=2.3 / 1000 \mathrm{~h})$ than ankle sprains $(\mathrm{IR}=1.3 / 1000 \mathrm{~h})$. Different results may be due to the differences in a study population (adolescent players vs. male professional players) and recording system. Increased emphasis on preventive training programmes and investigating the efficacy of various prophylactic taping and bracing techniques may be helpful in reducing the overall frequency of injuries (Deitch, et al., 2006), especially ankle sprain injuries. Almost half of the injuries described in our study were recurrent or pre-existing injuries $(48 \%)$. A high number of recurrent injuries (28\%), mostly ankle sprains (79\%) (Passanen, et al., 2017), have been reported, thus highlighting the importance of prevention efforts considering the increased risk of recurrent sprain.

Acute injuries were most prevalent with $80 \%$, while $20 \%$ were described as chronic injuries. Cumps et al. (2007) reported significantly more acute than overuse injuries $(\mathrm{RR}=3.895 \% \mathrm{CI}$ : 1.2-2.1) as well. Acute injuries accounted for $83.8 \%$ to $95 \%$ of all injuries in another study (Emery, Rose, McAllister, \& Meeuwisse, 2007). Overall incidence of overuse injuries is not as frequent as acute injuries, but as the most frequent have been reported knee overuse injuries (Cumps, et al., 2007) and bone stress fractures (Khan, et al., 2018). Sports professionals should bear in mind that these injuries might have a more detrimental impact on short- and long-term player's performance and career length. The term 'overuse injury' is commonly applied to the gradual onset of injuries. However, this term is used inconsistently in literature (International Olympic Committee..., 2020). Furthermore, these data should be carefully interpreted because it is sometimes very hard for athletes, while selfreporting on their injuries, to distinguish these two onset mechanisms.

The practice injury rates were similar for females and males $(0.85 / 1000 \mathrm{~h}$ vs. $0.94 / 1000 \mathrm{~h})$, but the game injury rates were significantly higher for female players $(I R=43.7 / 1000 \mathrm{~h}$ vs. $I R=24.2 / 1000 \mathrm{~h})$, putting them at almost a twice higher risk than their male counterparts. The higher game-related injury rate in female-WNBA players than in male-NBA players was reported by Deitch et al. (2006). As expected, the rate of injuries was higher during games than during practices. Higher injury rates during games are not surprising and have been reported in other studies (Agel, et al., 2007; Baker, et al., 2020; Meeuwisse, et al., 2003; Messina, et al., 1999; Pasanen, et al., 2007). The increased exposure may be related to an increased risk of injury due to a repetitive and cumulative trauma (Agel, et al., 2007). Therefore, not surprisingly, we found those athletes who were more exposed to competition (reported more than 20 min of on-court time per game) were at a twice higher risk of injury $(\mathrm{OR}=2.1)$ compared to their counterparts who played less than 
20 minutes per game. Player-to-player contact, increased intensity, and uncontrolled game situations are likely factors contributing to this increased injury rate (Baker, et al., 2020) and athletes who spend more time on the court, in game, experience more risk situations. However, Caparrós, Casals, Solana, and Peña (2018) found unloaded players with inadequate management of training loads to have a higher risk of injury. They suggested that adequate management of training loads might be a relevant factor to reduce the likelihood of injury occurrence. This is supported by Weiss, Allen, McGuigan, and Whatman (2017) who also found a decreasing trend of injuries if the proper management of workload ratio was applied (workloads between 1-1.5).

The consistent findings of a high frequency of injuries have led to the development of prevention programmes of which the most popular is the one developed for soccer that aims to reduce the rates of injuries in football. The FIFA 11+ programme was then implemented and evaluated as an injury prevention programme in basketball in a randomised control study by Longo et al. (2012). They found The FIFA 11+ to be effective in reducing overall injuries, training injuries, lower extremity, acute, and severe injuries. However, no statistically significant difference in match, knee, ankle, and overuse injuries was found between the control and intervention groups. Another highly valued study which aimed to examine the effectiveness of a balance training programme in reducing injury in high-school basketball was conducted by Emery et al. (2007). They found a basketball-specific balance training programme was protective of acute-onset injuries in high-school basketball, but they also did not find statistically significant reduction in ankle sprain injuries. On the contrary, secondary analysis of data pooled from five studies (Owoeye, Palacios-Derflingher, \& Emery, 2018) showed that a neuromuscular warm-up programme had preventive effect in reducing the risk of ankle sprain injuries by $32 \%$. Furthermore, Taylor et al. (2015) have done a meta-analysis examining the effectiveness of lower extremity prevention programmes in basketball. Their results on 10 studies showed that prophylactic programmes significantly reduced the incidence of general lower extremity injuries and ankle sprains particularly. These results indicate that preventive interventions such as neuromuscular training programmes may be effective, therefore, they should be implemented to reduce the rates and risks of injury occurrence in basketball.

The aim of this study was to retrospectively analyse the occurrence of injuries among the Croatian professional basketball players according to gender and their playing position, and to associate these injuries with intrinsic (age, body height and body mass) and extrinsic factors (duration of training sessions and the number of practice hours per week). The results of this study must be interpreted within the context of its design and several limitations need to be considered when interpreting the results. The main limitation of this study was its retrospective design and we relied on participants' memory, so the recall bias is very limiting. Furthermore, if the teams' medical staff had participated in injury report, the data would have been more precisely and accurately recorded. Namely, it difficult for the players to distinguish between the acute and chronic mechanisms and various injury types, despite detailed verbal instructions from the data collectors. When injury rates were calculated, exposure recording was a very important issue. In our study, game and training exposure was calculated using the self-reported average participation. It is also possible that athletes who were injured overestimated their participation time, thus overestimating the overall exposure. Nevertheless, the data were collected in the same manner for all the teams so the recall bias and level of uncertainty can be assumed to be comparable among the genders and playing positions. Another limitation of this study is that the data period was limited to one season. The reliability and accuracy of this study would have been improved had we included all the first league players, had the medical staff contributed their available injury records, and had the design of the study been prospective across multiple seasons. Nevertheless, this is the first descriptive epidemiological study estimating injury rates and risks among the Croatian professional basketball players. The main strength of this study is a relatively large sample size, which included almost all clubs and players of the First Croatian National League. Further research should focus on the epidemiology of injuries using prospective design over multiple seasons providing the consistency of the record and clinical practice over the study duration. Systematic approach, return-to-play time, the medical staff members recruitment, and rigorous exposure time recording would ensure more power, consistency, and generalizability to the future findings. 


\section{References}

Agel, J., Olson, D.E., Dick, R., Arendt, E.A., Marshall, S.W., \& Sikka, R.S. (2007). Descriptive epidemiology of collegiate women's basketball injuries: National Collegiate Athletic Association Injury Surveillance System, 1988-1989 through 2003-2004. Journal of Athletic Training, 42(2), 202.

Andreoli, C.V., Chiaramonti, B.C., Biruel, E., de Castro Pochini, A., Ejnisman, B., \& Cohen, M. (2018). Epidemiology of sports injuries in basketball: Integrative systematic review. BMJ Open Sport and Exercise Medicine, 4(1), e000468. doi: 10.1136/bmjsem-2018-000468

Arendt, E.A., Agel, J., \& Dick, R. (1999). Anterior cruciate ligament injury patterns among collegiate men and women. Journal of Athletic Training, 34(2), 86.

Baker, H., Rizzi, A., \& Athiviraham, A. (2020). Injury in the Women's National Basketball Association (WNBA) from 2015 to 2019. Arthroscopy, Sports Medicine, and Rehabilitation, 2(2), e213-e217. doi: 10.1016/j.asmr.2020.02.003

Benis, R., La Torre, A., \& Bonato, M. (2018). Anterior cruciate ligament injury profile in female elite Italian basketball league. Journal of Sports Medicine and Physical Fitness, 58(3), 280-286. doi: 10.23736/S0022-4707.16.06663-9

Caparrós, T., Casals, M., Solana, Á., \& Peña, J. (2018). Low external workloads are related to higher injury risk in professional male basketball games. Journal of Sports Science and Medicine, 17(2), 289.

Cumps, E., Verhagen, E., \& Meeusen, R. (2007). Prospective epidemiological study of basketball injuries during one competitive season: Ankle sprains and overuse knee injuries. Journal of Sports Science and Medicine, 6(2), 204.

Deitch, J.R., Starkey, C., Walters, S.L., \& Moseley, J.B. (2006). Injury risk in professional basketball players: A comparison of Women's National Basketball Association and National Basketball Association athletes. The American Journal of Sports Medicine, 34(7), 1077-1083. doi: 10.1177/0363546505285383

Drakos, M.C., Domb, B., Starkey, C., Callahan, L., \& Allen, A.A. (2010). Injury in the National Basketball Association: A 17-year overview. Sports Health, 2(4), 284-290. doi: 10.1177/1941738109357303

Emery, C.A., Rose, M.S., McAllister, J.R., \& Meeuwisse, W.H. (2007). A prevention strategy to reduce the incidence of injury in high school basketball: A cluster randomized controlled trial. Clinical Journal of Sport Medicine, 17(1), 17-24. doi: 10.1097/JSM.0b013e31802e9c05

Finch, C. (2006). A new framework for research leading to sports injury prevention. Journal of Science and Medicine in Sport, 9(1-2), 3-9. doi: 10.1016/j.jsams.2006.02.009

Fuller, C.W., Ekstrand, J., Junge, A., Andersen, T.E., Bahr, R., Dvorak, J., Hägglund, M., McCrory, P., \& Meeuwisse, W.H. (2006). Consensus statement on injury definitions and data collection procedures in studies of football (soccer) injuries. British Journal of Sports Medicine, 40, 193-201. doi: 10.1136/bjsm.2005.025270

Harmer, P.A. (2005). Basketball injuries. In N. Maffulli \& D.J. Caine (Eds.), Epidemiology of pediatric sports injuries: Team sports (Vol. 49, pp. 31-61). Basel: Karger Publishers. doi: 10.1159/000085341

Henry, J.H., Lareau, B., \& Neigut, D. (1982). The injury rate in professional basketball. The American Journal of Sports Medicine, 10(1), 16-18. doi: 10.1177/036354658201000104

Herzog, M.M., Mack, C.D., Dreyer, N.A., Wikstrom, E.A., Padua, D.A., Kocher, M.S., ..., \& Marshall, S.W. (2019). Ankle sprains in the National Basketball Association, 2013-2014 through 2016-2017. The American Journal of Sports Medicine, 47(11), 2651-2658. doi: 10.1177/0363546519864678

International Olympic Committee Injury and Illness Epidemiology Consensus Group, Bahr, R., Clarsen, B., Derman, W., Dvorak, J., Emery, C.A., ..., \& Khan, K.M. (2020). International Olympic Committee Consensus Statement: Methods for recording and reporting of epidemiological data on injury and illness in sports 2020 (Including the STROBE Extension for Sports Injury and Illness Surveillance [STROBE-SIIS]). Orthopaedic Journal of Sports Medicine, 8(2). doi: 10.1177/2325967120902908

Khan, M., Madden, K., Burrus, M.T., Rogowski, J.P., Stotts, J., Samani, M.J., ..., \& Bedi, A. (2018). Epidemiology and impact on performance of lower extremity stress injuries in professional basketball players. Sports Health, 10(2), 169-174. doi: 10.1177/1941738117738988

Kofotolis, N., \& Kellis, E. (2007). Ankle sprain injuries: A 2-year prospective cohort study in female Greek professional basketball players. Journal of Athletic Training, 42(3), 388.

Longo, U.G., Loppini, M., Berton, A., Marinozzi, A., Maffulli, N., \& Denaro, V. (2012). The FIFA 11+ program is effective in preventing injuries in elite male basketball players: A cluster randomized controlled trial. The American Journal of Sports Medicine, 40(5), 996-1005.

Meeuwisse, W.H., Sellmer, R., \& Hagel, B.E. (2003). Rates and risks of injury during intercollegiate basketball. The American Journal of Sports Medicine, 31(3), 379-385. doi: 10.1177/03635465030310030901

Messina, D.F., Farney, W.C., \& DeLee, J.C. (1999). The incidence of injury in Texas high school basketball. The American Journal of Sports Medicine, 27(3), 294-299. doi: 10.1177/03635465990270030401

Moreira, P., Gentil, D., \& de Oliveira, C. (2003). Prevalência de lesões na temporada 2002 da Seleção Brasileira Masculina de Basquete. [Prevalence of injuries of Brazilian Basketball National Team during 2002 season. In Portuguese.] Revista Brasileira de Medicina do Esporte, 9(5), 258-262. https://doi.org/10.1590/S1517-86922003000500002

Neto, A.P., \& de Castro César, M. (2005). Body composition assessment in male basketball players in Brazilian National Basketball League 2003. Revista Brasileira de Cineantropometria e Desempenho Humano, 7(1), 35-44. doi: $10.1590 / \% 25 x$ 
Ostojic, S.M., Mazic, S., \& Dikic, N. (2006). Profiling in basketball: Physical and physiological characteristics of elite players. Journal of Strength and Conditioning Research, 20(4), 740. doi: 10.1519/R-15944.1

Owoeye, O.B.A., Akodu, A.K., Oladokun, B.M., \& Akinbo, S.R.A. (2012). Incidence and pattern of injuries among adolescent basketball players in Nigeria. Sports Medicine, Arthroscopy, Rehabilitation, Therapy and Technology, 4(1), 15. doi: 10.1186/1758-2555-4-15

Owoeye, O.B., Ghali, B., Befus, K., Stilling, C., Hogg, A., Choi, J., ..., \& Emery, C.A. (2020). Epidemiology of allcomplaint injuries in youth basketball. Scandinavian Journal of Medicine and Science in Sports, 3(12), 24662476. doi: 10.1111/sms.13813

Owoeye, O.B., Palacios-Derflingher, L.M., \& Emery, C.A. (2018). Prevention of ankle sprain injuries in youth soccer and basketball: Effectiveness of a neuromuscular training program and examining risk factors. Clinical Journal of Sport Medicine, 28(4), 325-331. doi: 10.1097/JSM.0000000000000462

Pasanen, K., Ekola, T., Vasankari, T., Kannus, P., Heinonen, A., Kujala, U.M., \& Parkkari, J. (2017). High ankle injury rate in adolescent basketball: A 3-year prospective follow-up study. Scandinavian Journal of Medicine and Science in Sports, 27(6), 643-649. doi: 10.1111/sms.12818

Rodas, G., Bove, T., Caparrós, T., Langohr, K., Medina, D., Hamilton, B., ..., \& Casals, M. (2019). Ankle sprain versus muscle strain injury in professional men's basketball: A 9-year prospective follow-up study. Orthopaedic Journal of Sports Medicine, 7(6), 2325967119849035. doi: 10.1177/2325967119849035

Taylor, J.B., Ford, K.R., Nguyen, A.D., Terry, L.N., \& Hegedus, E.J. (2015). Prevention of lower extremity injuries in basketball: A systematic review and meta-analysis. Sports Health, 7(5), 392-398. doi: 10.1177/1941738115593441

Tummala, S.V., Hartigan, D.E., Makovicka, J.L., Patel, K.A., \& Chhabra, A. (2018). 10-year epidemiology of ankle injuries in men's and women's collegiate basketball. Orthopaedic Journal of Sports Medicine, 6(11), 2325967118805400. doi: $10.1177 / 2325967118805400$

Vanderlei, F.M., Bastos, F.N., de Lemes, Í.R., Vanderlei, L.C.M., Júnior, J.N., \& Pastre, C.M. (2013). Sports injuries among adolescent basketball players according to position on the court. International Archives of Medicine, 6(1), 1-4. doi: 10.1186/1755-7682-6-5

Weiss, K.J., Allen, S.V., McGuigan, M.R., \& Whatman, C.S. (2017). The relationship between training load and injury in men's professional basketball. International Journal of Sports Physiology and Performance, 12(9), 12381242. doi: 10.1123/ijspp.2016-0726

Zelisko, J.A., Noble, H.B., \& Porter, M. (1982). A comparison of men's and women's professional basketball injuries. The American Journal of Sports Medicine, 10(5), 297-299. doi: 10.1177/036354658201000507

Zuckerman, S.L., Wegner, A.M., Roos, K.G., Djoko, A., Dompier, T.P., \& Kerr, Z.Y. (2018). Injuries sustained in National Collegiate Athletic Association men's and women's basketball, 2009/2010-2014/2015. British Journal of Sports Medicine, 52(4), 261-268. doi: 10.1136/bjsports-2016-096005

Submitted: January 22, 2021

Accepted: May 20, 2021

Published Online First: June 16, 2021

Correspondence to:

Matilda Šola, M.Sc.

University of Zagreb, Faculty of Kinesiology

E-mail: matilda.sola@gmail.com 